\title{
Determination of the Heat Stability Profiles of Concentrated Milk and Milk Ingredients Using High Resolution Ultrasonic Spectroscopy
}

\author{
L. Lehmann and V. Buckin \\ Department of Chemistry, University College Dublin, Belfield, Dublin 4
}

\section{ABSTRACT}

In the present work, we used high resolution ultrasonic spectroscopy for the analysis of heat coagulation process in milks. Two skim milks recombined from powder samples differing by their preheating treatments as well as dairy ingredients (phosphocasein, whey protein isolate, and a milk model) were monitored while submitted to a temperature of $120^{\circ} \mathrm{C}$. Three stages in the precoagulation and coagulation processes can be distinguished in the ultrasonic velocity and attenuation profiles. The first stage shows a very sharp decrease in ultrasonic velocity and increase in ultrasonic attenuation. This could be attributed to fast denaturation and aggregation of whey proteins and precipitation of calcium phosphate. In the second stage, small changes in ultrasonic velocity are observed, the rate of which depends on the nature and $\mathrm{pH}$ of the samples. In the third stage, a sharp decrease in ultrasonic velocity and attenuation is recorded for all samples, which corresponds to the coagulation and formation of the gel network. After coagulation, a very small change in ultrasonic velocity and attenuation was observed. From the ultrasonic measurements, we determined the heat stability vs. $\mathrm{pH}$ profiles of the different samples studied. The observed ultrasonic attenuation profiles were also interpreted in terms of changes in the size of casein micelles and coagulation processes.

(Key words: high resolution ultrasonic spectroscopy, concentrated milk, heat stability, ultrasonic velocity)

Abbreviation key: HCT = heat coagulation time, HRUS = high resolution ultrasonic spectroscopy, REM = recombined evaporated milk, SMP = skim milk powder, SMUF = simulated milk ultrafiltrate, $\mathbf{W P I}=$ whey protein isolate.

\section{INTRODUCTION}

The ability of milk to withstand high processing temperatures is one of the key factors in modern dairy

Received July 16, 2004.

Accepted May 30, 2005.

Corresponding author: V. Buckin; e-mail: buckinv@eircom.net. technologies, as milk is almost always subjected to a heat treatment. The main purpose of heating milk is usually preservation, by killing microorganisms, by inactivating enzymes, and by some changes in chemical composition. Heat stability is an essential property when recombined evaporated milk (REM) prepared from skim milk powder (SMP) is exposed to high thermal treatments. An important feature of SMP is the heat treatment it has received before drying.

Numerous studies have been carried out in the field of assessment of the heat stability of milks and their ingredients. Sommer and Hart (1919) developed a heat stability test as early as 1919 . Various tests, similar in principle, have been subsequently devised (Sommer and Hart, 1922; Webb and Holm, 1932; Pyne and McHenry, 1955; Rose and Tessier, 1959; Belec and Jenness, 1962) until the 1960s when Davies and White (1966) published their subjective method that forms the basis of the 2 tests prevailing today: the Irish Dairy Board method and the Standard Association of Australia method. Both methods are based on the visual determination of heat coagulation of a milk sample at $120^{\circ} \mathrm{C}$. In the Irish method (Irish Dairy Board, 1974), a small milk sample (typically $2.5 \mathrm{~mL}$ ) is placed in a rocking sealed glass tube immersed in an oil bath maintained at constant temperature; the time required for particles of coagulated protein to become visible is recorded. Assay temperature, agitation rate, degree of tube fill, and angle of tilt influence the coagulation time determined by this method (Davies and White, 1966). The Australian method (Standard Association of Australia, 1978) uses bigger samples (30 mL) and operates on a discontinuous principle. The bottles containing the milk samples are taken out of the oil bath every $3 \mathrm{~min}$, shaken to check for flocculation, and then returned to the heating bath.

Other techniques have been suggested in the past for the determination of heat coagulation times (HCT). White and Davies (1966) determined HCT by following the percentage of total nitrogen remaining in dispersion after centrifugation. The use of this technique is favored if a detailed description of the heat coagulation process is required. Foissy and Kneifel (1984) developed an automatic method using an electromagnetic sensor device, 
and de Wit et al. (1986) measured HCT by increases in viscosity using a computer-linked, falling-ball viscometer called the Klaro-Graph. These automated techniques can be left unsupervised, but are destructive. Therefore, they have not been widely adopted in studies of the heat stability of milk.

In this work, we describe the application of novel high resolution ultrasonic spectroscopy (HRUS) for the study of heat stability of 2 REM samples submitted to different preheat treatments and of milk ingredients such as casein and whey proteins. High resolution ultrasonic spectroscopy is a novel analytical technique with high potential for analyses of a wide range of samples and molecular processes (Buckin and O'Driscoll, 2002). It presents various advantages such as being fast, noninvasive, highly sensitive, and able to perform measurements in optically opaque systems. It also allows continuous monitoring of the changes happening in milk while submitted to a high temperature, which is difficult using other techniques. This technique is based on the precise measurements of parameters of ultrasonic waves propagating through the samples. Ultrasonic parameters are extremely sensitive to the molecular organization and molecular interactions in the samples and can be exploited in the analysis of a broad range of molecular processes (Povey et al., 1999; Kudryashov et al., 2000; Sigfusson et al., 2004). Until now, the use of ultrasonic spectroscopy for material analysis was restrained to certain areas because of a limited resolution and the need for large sample volumes $(\geq 10$ $\mathrm{mL}$ ). However, it is now possible to measure ultrasonic parameters to a very high resolution (down to $0.2 \mathrm{~mm} /$ $\mathrm{s}$ for ultrasonic velocity, which is up to 1000 times better than traditional ultrasonic techniques) in small volumes (down to $0.03 \mathrm{~mL}, 1 \mathrm{~mL}$ typically) and a broad range of sample types with modern commercial HRUS spectrometers. Monitoring both the ultrasonic attenuation, $\alpha$, and velocity, $u$, of milk samples submitted to high temperature allows the detection and analysis of molecular and structural transformations in the heat coagulation process.

In various studies, ultrasonic spectroscopy has been used to monitor and analyze different types of milk coagulation. Examples include the study of acidic coagulation as used in the process of making yogurt (Kudryashov et al., 2000; Buckin and Kudryashov, 2001) or rennet coagulation used for cheese making (Gunasekaran and Ay, 1996; Povey, 1997; Nassar et al., 2001). A study of heat-induced coagulation of calcium-fortified milk was previously carried out, leading to the development of calcium-fortified milk that is stable at temperatures $<100^{\circ} \mathrm{C}$ (Smyth et al., 1999). However, no study of ultrasonic parameters of milk has ever been achieved at temperatures $>100^{\circ} \mathrm{C}$. This is due to the fact that until recently ultrasonic devices did not provide the required temperature control at such high temperatures. Another problem was the requirement of sample pressurization to avoid boiling at temperatures $>100^{\circ} \mathrm{C}$. Introduction by Ultrasonic Scientific Ltd. (Dublin, Ireland) of the HRUS 102 spectrometer provides a new flexible tool perfectly adapted for these conditions. The measuring cells can easily be put under pressure and withstand a temperature of $120^{\circ} \mathrm{C}$. Under these conditions, the HRUS 102 spectrometer provides high precision measurements of both ultrasonic attenuation and velocity, thus allowing monitoring of phase transitions occurring in the sample. Processes such as enzymatic reactions, which are expected to produce only small changes in ultrasonic velocity (in the order of a few $\mathrm{cm} /$ s) require resolutions down to $0.5 \mathrm{~mm} / \mathrm{s}$ to be properly analyzed. This order of resolution can be achieved by HRUS, making it a very powerful analytical technique. In the present work, we used HRUS as a new method for the measurement and characterization of the heat stability and the coagulation curves of milk powder solutions and milk ingredients.

\section{MATERIALS AND METHODS}

\section{SMP}

Two SMP samples provided by The Dairy Products Research Centre, (Moorepark, Fermoy, Co. Cork, Ireland) and submitted to different preheat treatments were studied. The powders were obtained by evaporating milk to approximately $40 \%$ solids and drying it using a spray drier (Anhydro F1 lab 3, Copenhagen, Denmark) with an inlet temperature of 190 to $200^{\circ} \mathrm{C}$ and an outlet temperature of 90 to $95^{\circ} \mathrm{C}$. Prior to evaporation, milk, at normal milk solids, was either preheated minimally $\left(75^{\circ} \mathrm{C}\right.$ for $\left.15 \mathrm{~s}\right)$ or at typical levels $\left(120^{\circ} \mathrm{C}\right.$ for 2 min) used during heat-stable SMP manufacture. The former sample will be referred to as 'non-preheated' sample, and the latter as 'preheated' sample. The SMP were reconstituted at $20 \%$ TS by weight using deionized water, and $0.04 \%$ of sodium azide was added as a preservative.

The REM samples were then split into smaller samples, and their $\mathrm{pH}$ was adjusted to values covering the range from 6.0 to 7.0 using dilute $\mathrm{HCl}$ or dilute $\mathrm{NaOH}$. These samples were left overnight at room temperature to reach $\mathrm{pH}$ equilibrium, and their $\mathrm{pH}$ was measured before introducing them in the measuring cell to determine their coagulation time.

All of the milk ingredient solutions and milk model solutions were prepared using simulated milk ultrafiltrate (SMUF) at concentrated milk level $($ SMUF $\times 2)$ as a buffer. The SMUF $\times 2$ is a solution designed to maintain the salt composition at concentrated milk levels, 
which should aid in maintaining the integrity of the casein micellar system. The SMUF $\times 2$ was prepared following the method described by Jenness and Koops (1962), and its composition is as follows $(\mathrm{mg} / 100 \mathrm{~mL}$ ): $\mathrm{Ca}, 71.8$; Na, 84.0; K, 308.0, Mg, 15.6; P, 72.0; Cl, 230.0; citrate, 370.2; sulfate, 19.8; and $\mathrm{CO}_{2}, 19.0$.

\section{Phosphocasein}

Phosphocasein powder ( $84 \%$ proteins, 4 to $5 \%$ moisture, 1 to $2 \%$ lactose, 1 to $2 \%$ fat, and 7 to $8 \%$ ash) was obtained by following the procedure described by Kelly et al. (2000) and provided by The Dairy Products Research Centre (Moorepark, Co. Cork, Ireland). The samples were prepared by dissolving the correct amount of phosphocasein in SMUF $\times 2$ to obtain a $5 \%$ (by weight) protein solution (similar to the amount of phosphocasein present in 20\% solid reconstituted SMP); $0.04 \%$ sodium azide was added as a preservative.

The samples were then split into several smaller samples, and their $\mathrm{pH}$ was adjusted in the same manner as for the REM samples.

\section{Whey Protein}

Whey protein isolate (WPI) containing $89.6 \%$ protein (4 to $5 \%$ moisture and 5\% ash) was obtained from Davisco International Inc. (MN). The WPI solutions were prepared in the same manner as REM and phosphocasein. The sample contained $1.5 \%$ protein by weight, which is similar to the amount of whey protein present in $20 \%$ solid reconstituted SMP.

\section{Milk Model}

Milk model solutions were prepared by dissolution of phosphocasein and WPI in SMUF $\times 2$ at the same concentrations as previously used.

\section{Ultrasonic Measurements}

Ultrasonic parameters in the samples were measured using HR-US 102 high-resolution spectrometer (Ultrasonic Scientific, Dublin, Ireland) fitted with two 1-mL ultrasonic cells. The spectrometer can work in differential and single cell modes. In differential mode, one of the cells contains the sample, and the second is filled with the reference liquid; the difference in ultrasonic velocity between the cells is measured. The temperature controller, Haake F8 heating bath provided by the manufacturer of HR-US 102 device, allowed maintenance of the required temperature within $\pm 0.01^{\circ} \mathrm{C}$. Tetraethylene glycol was used as a heating liquid. The limiting resolution for measurements of ultrasonic ve- locity in differential mode was $\pm 0.2 \mathrm{~mm} / \mathrm{s}$. As our measurements did not require such high resolution, single cell mode was used in the current project. In this mode, the reference cell is not used, and ultrasonic velocity in the sample cell only is monitored. Single cell mode provides resolution at $\pm 1.5 \mathrm{~cm} / \mathrm{s}$ for ultrasonic velocity and down to $0.2 \%$ for ultrasonic attenuation. The device was calibrated with water, for which ultrasonic parameters are well known over a broad temperature range (Del Grosso and Mader, 1972).

We monitored several frequencies in the frequency range from 2.5 to $14 \mathrm{MHz}$. The ultrasonic velocity $u$ and attenuation $\alpha$ were automatically recorded during the coagulation process at $120^{\circ} \mathrm{C}$.

Ultrasonic velocity is the distance traveled by the wave through the sample per unit of time. Ultrasonic attenuation, $\alpha$, is defined by the exponential decay of the ultrasonic wave $\mathrm{A}=\mathrm{A}_{0} \mathrm{e}^{-\alpha \mathrm{x}}$, where $\mathrm{A}$ is the amplitude of the wave traveled a distance $\mathrm{x}$ in the sample and $\mathrm{A}_{0}$ is the initial amplitude of the wave.

\section{Pressure Control}

Because the experiments took place at a temperature exceeding the boiling point of milk $\left(120^{\circ} \mathrm{C}\right)$, the pressurization of the measuring cell was required. A TP1 handheld SI Pressure Instruments pneumatic pump (Birmingham, UK) was fitted to the measuring cell and used to maintain a constant pressure of 2 bar throughout the duration of the experiment. Once the cell was pressurized, the measurements were started. The times were adjusted afterward so that on every graph, $t=0$ corresponds to the time of injection of the sample into the measuring cell.

\section{Particle Sizing}

In homogeneous materials, velocity and attenuation are determined by intrinsic properties of the medium. Heterogeneous dispersions produce an additional 'scattering' contribution to ultrasonic velocity and attenuation, which is a function of particle size. In the long wavelength limit [i.e. when the wavelength of ultrasound $(\lambda)$ is much greater than the particle radius $(r)$ ], explicit expressions for the ultrasonic scattering in dispersions have been derived (Epstein and Carhart, 1953; Waterman and Truell, 1961; Allegra and Hawley, 1972; Povey, 1997). The basic mechanism of interaction of ultrasonic wave with particles in dispersions in this regime consists of 2 major contributors, thermoelastic and viscoinertial scattering. Thermoelastic scattering results from oscillations of temperature caused by the adiabatic compressions and decompressions in ultrasonic waves. These oscillations in temperature create 
a heat flow between the particle and the surroundings. This flow heats and cools the boundary layer between the particle and the surroundings with an associated expansion and contraction of the boundary layer, thus turning the particle into a secondary source of ultrasonic waves. In addition, a thermal wave will flow away from the particle and attenuate. The source of viscoinertial scattering lies in the difference in density between the scatterer and its surroundings. The oscillating forces associated with the deformation in the ultrasonic wave result in a motion of particles relative to their surroundings. This motion increases with increasing density difference between the particles and the surrounding fluid. The relative motion is a source of new waves and a shear field propagating away from the border between the particle and surrounding fluid, which attenuates away over a distance.

In the most comprehensive theories of ultrasonic scattering, the ultrasonic properties of an ensemble of scatterers are characterized in terms of a complex wave vector $K$. The Psize289 software provided by Ultrasonic Scientific Ltd. is based on the most widely used multiple scattering theoretical approaches (Epstein and Carhart, 1953; Waterman and Truell, 1961; Allegra and Hawley, 1972; Povey, 1997). This software utilizes theoretical relationships between the complex wave vector and the scattering coefficients, which are determined by the physical properties of the particles and the continuous medium.

\section{Subjective Method}

Analysis of the heat stability of REM was carried out according to the Irish Dairy Board (1974) method in the laboratory of The Dairy Products Research Centre (Moorepark, Co. Cork, Ireland) for comparison purposes.

\section{RESULTS}

Figure 1 shows the evolution of the ultrasonic velocity difference during heat coagulation of REM. The ultrasonic velocity difference of the samples was obtained by subtracting a reference value to the absolute ultrasonic velocity, so that it is equal to zero after coagulation. For convenience in this paper, "ultrasonic velocity" actually refers to the ultrasonic velocity difference. The general shape of the ultrasonic velocity profile is similar for all samples analyzed: milks, phosphocasein, whey protein, and milk model samples all show a similar ultrasonic velocity profile with individual differences in the slopes, times, and amplitudes of transitions. Only one measured frequency is shown in Figure 1, as there is no significant frequency dependence in ultrasonic velocity curves.

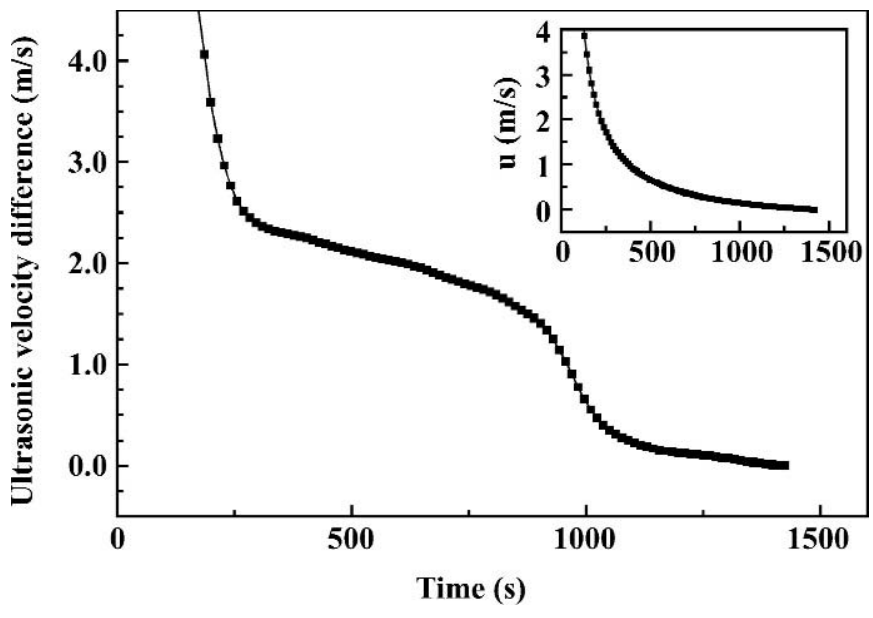

Figure 1. Profile of ultrasonic velocity difference in non-preheated recombined evaporated milk sample at its natural $\mathrm{pH}(6.47)$ at 5 $\mathrm{MHz}$. Inset: Profile of ultrasonic velocity difference (u) in deionized water at $5 \mathrm{MHz}$.

Four stages can be distinguished in the ultrasonic velocity heat-stability profile. In the first stage (from 0 to $300 \mathrm{~s}$ on Figure 1), ultrasonic velocity decreases sharply. This could be attributed to a number of processes, such as the denaturation of whey protein and precipitation of calcium phosphate onto the micelles that happen during the first few minutes of heating (van Boekel et al. 1989; Singh and Creamer, 1991a) and could induce a decrease in ultrasonic velocity caused by the hydration changes that accompany them. The initial decrease in velocity is also partly due to the thermal equilibration of the sample (i.e., the time taken by the sample to reach the holding temperature) as illustrated for deionized water in the inset in Figure 1. The second stage (between 300 and $850 \mathrm{~s}$ ), or precoagulation stage, shows small changes in ultrasonic velocity, the slope of which depends on the nature and $\mathrm{pH}$ of the samples. In the third stage (from 850 to $1100 \mathrm{~s}$ ), a sharp decrease in ultrasonic velocity is recorded, which could be attributed to the coagulation of the sample. Finally, the fourth stage (after $1100 \mathrm{~s}$ ) shows small changes in ultrasonic velocity. This corresponds to the end of the coagulation process.

The ultrasonic attenuation profiles of the different samples show a variety of shapes depending on the nature of the sample and its $\mathrm{pH}$, as can be seen in Figures 2 and 3 . This is expected as the scattering contribution to ultrasonic attenuation is highly dependent on particles sizes, which in turn are highly $\mathrm{pH}$ dependent (Devold et al., 2000). In samples containing casein micelles, a sharp initial increase in attenuation is followed by a further, slower increase. The heat coagulation (detected as a sharp decrease in ultrasonic velocity) 


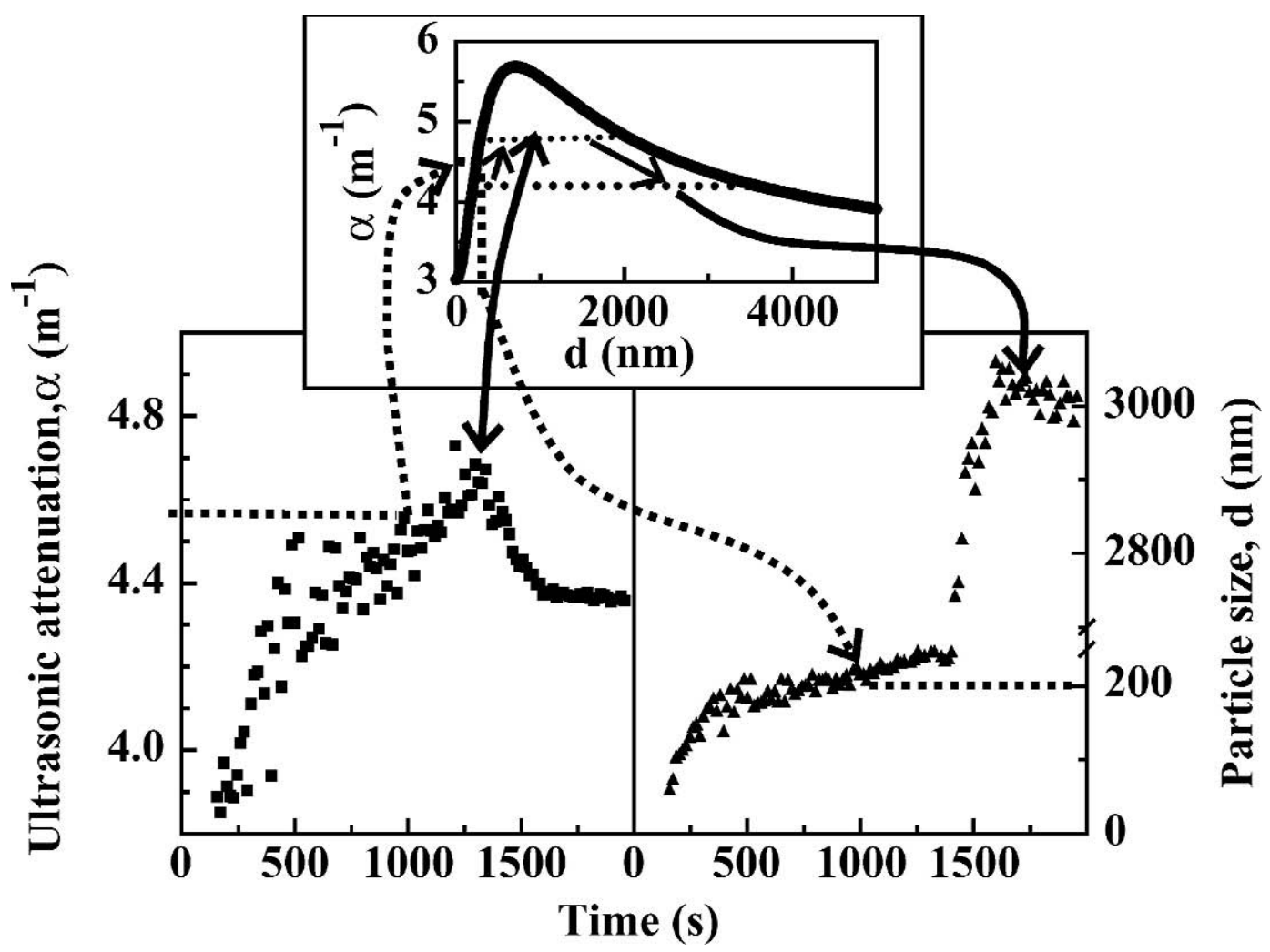

Figure 2. Ultrasonic attenuation profile at $2.5 \mathrm{MHz}$ of preheated recombined evaporated milk at $\mathrm{pH} 6.7(\mathbf{\square})$ and the corresponding particle size profile as determined by the Psize289 software $(\boldsymbol{\Delta})$. The top graph shows the dependence of ultrasonic attenuation with particle size for this sample.

is then marked by a sudden decrease in ultrasonic attenuation (Figure 2), which can sometimes be preceded by a peak in attenuation (Figure 3 ). In whey protein samples, attenuation increases very slowly initially. A

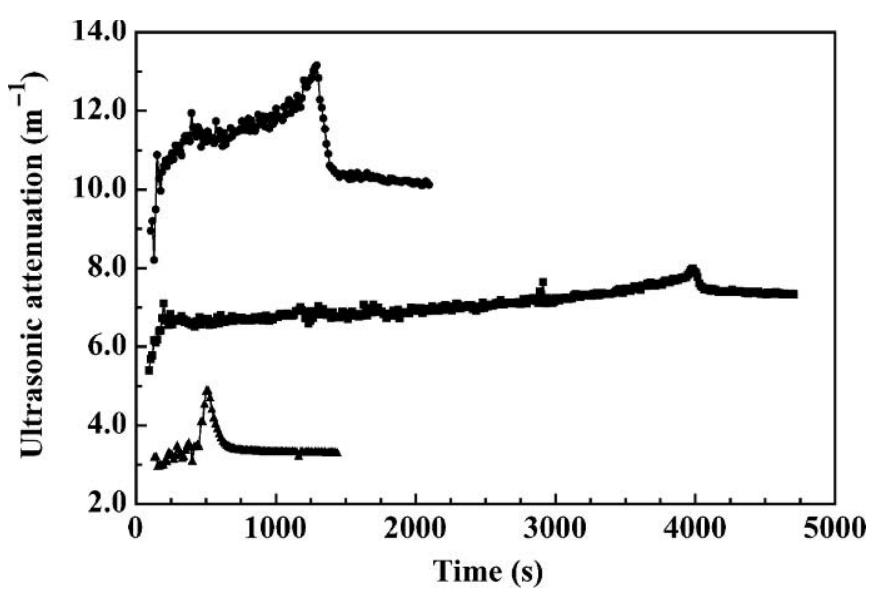

Figure 3. Ultrasonic attenuation profiles at $5 \mathrm{MHz}$ of the milk model (৩) and phosphocasein (ם) samples at their natural $\mathrm{pH}$ and the whey protein sample at pH $6.6(\mathbf{\Delta})$. peak in attenuation profile coincides with a sharp decrease in ultrasonic velocity (not shown on the figure) and can be attributed to a coagulation process.

The evolution of ultrasonic attenuation can be interpreted in terms of changes in particle sizes during coagulation process. Figure 2 shows an example of the use of the Psize289 software to estimate the changes in particle diameters with heating time.

The following physical parameters for dispersed and continuous phases were used in the calculations: 1) dispersed phase, density, $\rho=1076 \mathrm{~kg} / \mathrm{m}^{3}$; specific heat capacity, $\mathrm{Cp}=3818 \mathrm{~J} / \mathrm{kg}$ of $\mathrm{K}$; thermal conductivity, $\kappa=0.521 \mathrm{~J} / \mathrm{ms}$ per $\mathrm{K}$, ultrasonic velocity, $\mathrm{u}=1563 \mathrm{~m} /$ $\mathrm{s}$; shear modulus, $\mu=0.298 \mathrm{GPa}$; thermal expansion coefficient, $\beta=3.1 \times 10^{-4} \mathrm{~K}^{-1}$, and the attenuation at $2.5 \mathrm{MHz}, \alpha=19.37 \mathrm{~m}^{-1} ; 2$ ) continuous phase, viscosity, $\eta_{0}=2.83 \times 10^{-4} \mathrm{~Pa} / \mathrm{s}$, density, $\rho_{\mathrm{o}}=943.4 \mathrm{~kg} / \mathrm{m}^{3}$, specific heat capacity, $\mathrm{Cp}_{0}=4246 \mathrm{~J} / \mathrm{kg}$ per $\mathrm{K}$, thermal conductivity, $\kappa_{0}=0.675 \mathrm{~J} / \mathrm{ms}$ per $\mathrm{K}$, ultrasonic velocity, $\mathrm{u}_{0}=1516$ $\mathrm{m} / \mathrm{s}$, thermal expansion coefficient, $\beta_{0}=9.0 \times 10^{-4} \mathrm{~K}^{-1}$, and the attenuation at $2.5 \mathrm{MHz}, \alpha_{0}=0.156 \mathrm{~m}^{-1}$. This set of parameters is based on data obtained by Griffin and Griffin (1990) for a temperature of $20^{\circ} \mathrm{C}$. To correct 
the parameters of continuous medium for temperature difference, we have modified the original values given by Griffin and Griffin (1990) by the amount typically observed in liquids for an increase in temperature of $100^{\circ} \mathrm{C}$ (Smithsonian Institution, 1920; Schaaffs, 1967; American Institute of Physics, 1972; Yaws, 1977; Brandrup and Immergut, 1989; CRC Handbook of Chemistry and Physics, 2000). The parameters for dispersed phase were not corrected, as typically solids show small variation of the parameters with temperature ( $\leq 20 \%$ between room temperature and $120^{\circ} \mathrm{C}$ ).

To evaluate the effect of possible inaccuracy in physical parameters on our estimations, we have varied reasonable combinations of the parameters by a $\pm 50 \%$ change of Griffins' values (for both dispersed and continuous phases) and observed that the maximum on attenuation vs. particle size curve (Figure 2) always remained between 400 and $1000 \mathrm{~nm}$ and exceeds the size of casein micelles by several times (Carroll et al., 1971; McMahon and Brown, 1984). In addition, we have found that viscosity (viscous scattering contribution) does not have a significant effect on attenuation in our systems.

Overall, the uncertainty in extrapolated to $120^{\circ} \mathrm{C}$ physical properties of continuous medium and the particles does not allow exact calculation of particle size in our system. However, regardless of this, qualitative analysis of the aggregation processes can be performed based on the shape of ultrasonic attenuation profiles. Therefore, the position of the maximum of the attenuation vs. particle size curve above $400 \mathrm{~nm}$ allows us to conclude that initially, the evolution of ultrasonic attenuation follows the left (rising) side of the curve and that the initial increase in attenuation could then be interpreted as an increase in the size of casein micelles. In milk, Freeman and Mangino (1981) showed that initial heat-induced micellar growth was followed by micellar disintegration, inducing complex changes in particle sizes. In concentrated milk, however, Singh and Creamer (1991a,b) reported that heat treatments caused an increase in average size of the casein micelles and reduced the number of smaller micelles, which is coherent with our results. They also observed increased dissociation of casein from the micelles with heating time and interpreted this by the fact that in concentrated milk, micellar aggregation, and dissociation occur simultaneously.

Upon coagulation, fast formation of large aggregates exceeding $1000 \mathrm{~nm}$ effective average diameter induces a slide to the right (falling) part of the curve. Therefore, a further increase in size then causes a decrease in attenuation.

The frequency dependence of ultrasonic attenuation is illustrated in Figure 4. An increase in ultrasonic attenuation is observed with increasing frequency. At all frequencies, coagulation of the sample is marked by a drop in attenuation. Quantitative analysis of the frequency dependence of ultrasonic attenuation is the object of ongoing work and will be presented in a future paper.

\section{DISCUSSION}

We used the following empirical algorithm for the analysis of the kinetic profile of ultrasonic velocity. This profile was fitted with an S-shaped curve, as shown in Figure 5 . The general equation used is given by

$$
\begin{gathered}
u=u_{0}+\frac{\Delta u}{\left(1+b \cdot e^{-v\left(t-t_{t}\right)}\right)^{1 / b}} \\
+(m-n) t\left(1-\frac{1}{1+e^{-v\left(t-t_{t}\right)}}\right)+n t
\end{gathered}
$$

where $u_{0}$ is the average velocity before transition (initial velocity), $\Delta u$ is the amplitude of the velocity change caused by the transition, $t_{t}$ is the time of transition (inflection point), $v$ is the transition rate, $b$ is controlled by where the inflexion point of the transition occurs (nearer the lower or upper asymptote), the slope of the velocity profile before transition is given by $(m+n)$ and $n$ is the slope after transition.

The parameters obtained by applying this algorithm to the experimental velocity data allow for the determination of the HCT for the various samples studied. Therefore, it is possible to determine their HCT-pH profiles.

The analysis of the ultrasonic attenuation profiles provides another way of determining the HCT of samples. Because the shape of attenuation profiles varies with the nature and $\mathrm{pH}$ of the samples, no systematic analysis was carried out. However, in cases where the attenuation profile shows a similar shape as the velocity profiles, the same algorithm was used for its analysis (Figure 5a). In other cases (Figure 5b), no mathematical analysis was carried out. As can be seen in Figure 5(a and b) however, the transition is visible and happens simultaneously on both velocity and attenuation profiles.

In the case of fast coagulating samples $(<5 \mathrm{~min})$, the transition happens during the thermal equilibration stage and is not clearly visible on the velocity profile, as it is "masked" by the sharp initial decrease in velocity. The transition can generally be seen on the attenuation profile, however. This illustrates the benefit of simultaneously monitoring both ultrasonic velocity and attenuation.

The HCT-pH profiles determined by ultrasonic measurements are shown on Figure 6 and 7 for REM and 


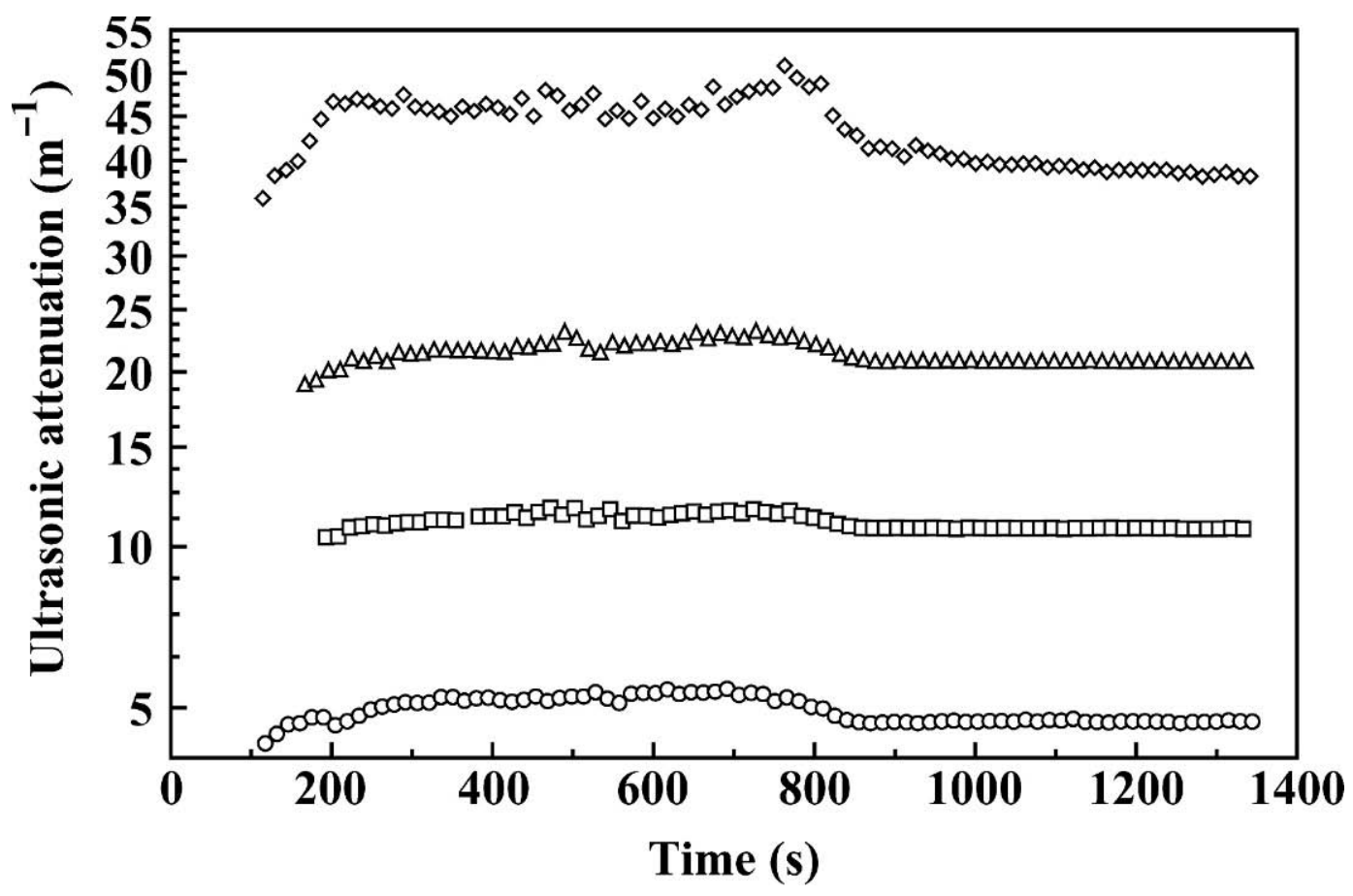

Figure 4. Ultrasonic attenuation of a non-preheated recombined evaporated milk sample at pH 6.4 at $2.5(\bigcirc), 5(\square), 8(\triangle)$, and $14 \mathrm{MHz}(\diamond)$.

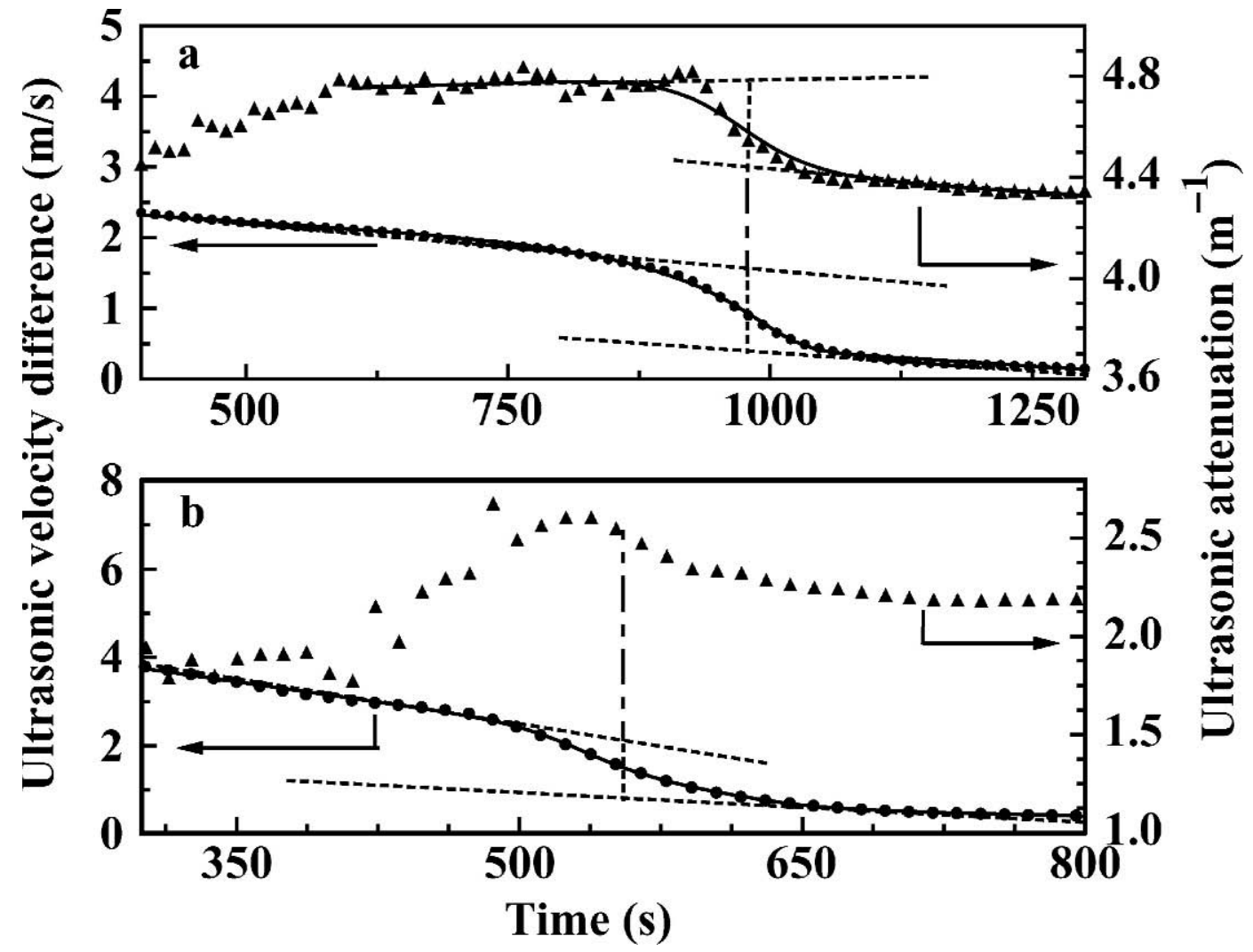

Figure 5. Experimental ultrasonic velocity difference $(\bullet)$ and attenuation $(\mathbf{\Delta})$ profile at $2.5 \mathrm{MHz}$ and S-shape fitting (solid lines) of the velocity and attenuation for non-preheated recombined evaporated milk sample at its natural $\mathrm{pH}$ (a) and whey protein solution at $\mathrm{pH} 6.6$ (b). 


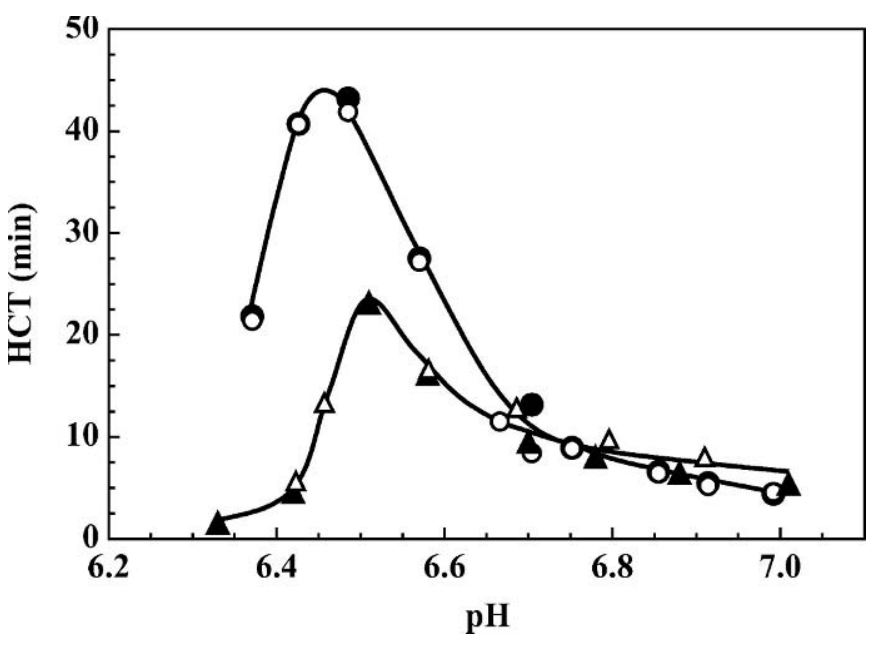

Figure 6. Heat stability profiles of non-preheated $(\boldsymbol{\Delta}, \triangle)$ and preheated recombined evaporated milk $(\bullet, \bigcirc)$ determined by the Irish Dairy Board method (solid symbols) and the ultrasonic method (open symbols). HCT = heat coagulation time.

milk ingredients, respectively. The stability profiles of REM samples obtained by ultrasonic measurements were compared with the profiles obtained by the Irish Dairy Board method (Figure 6). The same pH dependence of the HCT is observed in the profiles obtained by those 2 methods. Overall, there is a good correlation between HRUS and the Irish Dairy Board method. However, exact positions of some points are slightly different. This could be attributed to the different conditions in which milk is coagulating in the 2 methods. For example, while the milk was submitted to intense agitation and contact with air in the Irish Dairy Board method, it was kept still during ultrasonic measure-

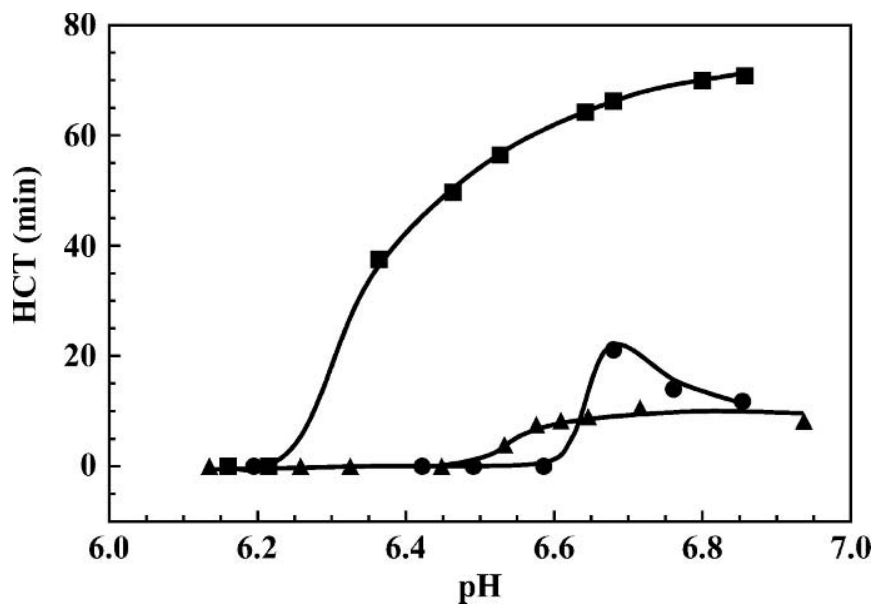

Figure 7. Heat stability profiles determined by the ultrasonic method for the milk model (@), phosphocasein (ם), and whey protein samples $(\boldsymbol{\Delta})$. HCT $=$ heat coagulation time. ments. Interactions between the milk sample and airsurface effects present in the first case may shift slightly the coagulation time compared with coagulation in the bulk of the sample as it occurs in the ultrasonic method. In the subjective method, the lumps are detected visually on the walls of the tube while, in the ultrasonic method, the overall gelation process is detected in the bulk of the sample. However, the good correlation between the HCT profiles obtained by different methods show that the HRUS technique is an adequate new tool for the measurement of heat stability in milk.

The profile of whey protein obtained by ultrasonic measurements (Figure 7) is in good agreement with the results presented by Rattray and Jelen (1997). However, their value of the HCT of whey protein is negligible from 6.4 to 6.9 , but, in our profile, a significant HCT is recorded at $\mathrm{pH} \geq 6.5$. This discrepancy can be explained by the fact that Rattray and Jelen (1997) prepared their samples using whey protein concentrate while we use WPI. Their samples would therefore contain a significant amount of lactose that our samples lack. When exposed to high temperature, lactose undergoes several reactions causing the formation of organic acid and is therefore a major source of heat-induced acidity, which could decrease the coagulation times observed in their samples compared to ours.

The stability profile obtained by ultrasonic measurements for phosphocasein (Figure 7) is in good agreement with the results obtained by Kelly et al. (2000) with the subjective Irish Dairy Board method. The $\mathrm{pH}$ dependence observed with both methods is similar, but the absolute values of the coagulation times are different. This can easily be explained by the fact that Kelly carried out the coagulations experiment at $140^{\circ} \mathrm{C}$, but the results presented in this work were obtained at $120^{\circ} \mathrm{C}$.

\section{CONCLUSIONS}

High resolution ultrasonic spectroscopy is an efficient tool for the investigation of the heat stability of milk powders and ingredients. We showed that it could be used for the determination of heat stability profiles of milk samples and milk ingredients. Further work will be carried out on quantitative analyses of ultrasonic coagulation profiles to show how real-time measurements of the ultrasonic parameters during the heat coagulation process allow real-time monitoring of the microstructural changes in milk exposed to high temperature.

\section{ACKNOWLEDGMENTS}

This work was supported by grant $00 / \mathrm{R} \& \mathrm{D} / \mathrm{TD} / 59$ from the Department of Agriculture and Food of Ire- 
land. We also acknowledge Phil Kelly, Brendan O'Kennedy, and Elaine Duggan, who provided us with samples and the characterization of their heat stability by the Irish Dairy Board method and for the helpful discussion of the results of this work.

\section{REFERENCES}

Allegra, J. R., and S. A. Hawley. 1972. Attenuation of sound in suspensions and emulsions: Theory and experiments. J. Acoust. Soc. Am. 51:1545-1564.

American Institute of Physics. 1972. American Institute of Physics Handbook. 3rd ed. McGraw-Hill, London, UK.

Belec, J., and R. Jenness. 1962. Dephosphorization of casein by heat treatment-II. In skim milks. J. Dairy Sci. 45:20-26.

Brandup, J., and E. H. Immergut, ed. 1989. Polymer Handbook. 3rd ed. John Wiley and Sons, New York, NY.

Buckin, V., and E. Kudryashov. 2001. Ultrasonic shear wave rheology of weak particle gels. Adv. Colloid Interface Sci. 89-90:401-422.

Buckin, V., and B. O'Driscoll. 2002. Ultrasonic waves and material analysis: Recent advances and future trends. Lab. Plus Int. 16(3):17-21.

Carroll, R. J., M. P. Thompson, and P. Melnychyn. 1971. Gelation of concentrated skimmilk: Electron microscopic study. J. Dairy Sci. $54: 1245-1252$.

CRC. 2000. CRC Handbook of Chemistry and Physics: A ReadyReference Book of Chemical and Physical Data. 81st ed. CRC, Boca Raton, FL.

Davies, D. T., and J. C. D. White. 1966. The stability of milk protein to heat-I. Subjective measurement of heat stability of milk. J. Dairy Res. 33:67-81.

Del Grosso, V. A., and C. W. Mader. 1972. Speed of sound in pure water. J. Acoust. Soc. Am. 52(5):1442-1446.

Devold, T. G., M. J. Brovold, T. Langsrud, and G. E. Vegarud. 2000. Size of native and heated casein micelles, content of protein and minerals in milk from Norwegian Red Cattle-Effect of milk protein polymorphism and different feeding regimes. Int. Dairy J. 10:313-323.

deWit, J. N., G. Klarenbeek, and C. de Graaf. 1986. The Klaro-Graph: A new instrument for measuring viscosity, density and heat stability of milk and milk concentrates at temperatures up to $140^{\circ} \mathrm{C}$. Voedingsmiddelen Technol. 19:25-27.

Epstein, P. S., and R. R. Carhart.1953. The absorption of sound in suspensions and emulsions. I. Water fog in air. J. Acoust. Soc. Am. 25:553-565.

Foissy, H., and W. Kneifel. 1984. An automatic method for measuring the heat coagulation time of milk powder solutions. J. Dairy Res. $51: 325-329$

Freeman, N. W., and M. E. Mangino. 1981. Effects or ultra-high temperature processing on size and appearance of casein micelles in bovine milk. J. Dairy Sci. 64:1772-1780.

Griffin, W. G., and M. C. A. Griffin. 1990. The attenuation of ultrasound in aqueous suspensions of casein micelles from bovine milk. J. Acoust. Soc. Am. 87:2541-2550.

Gunasekaran, S., and C. Ay. 1996. Milk coagulation cut-time determination using ultrasonics. J. Food Process Eng. 19:63-73.

Irish Dairy Board, Product Development Division. 1974. A Bord Bainne oil bath manual including methodology for the determination of the heat stability of skim-milk powder. Irish Dairy Board, Dublin, Ireland.

Jenness, R., and J. Koops. 1962. Preparation and properties of a salt solution which simulates milk ultrafiltrate. Neth. Milk Dairy J. 16(3):153-164.
Kelly, P. M., J. Kelly, R. Mehra, D. J. Oldfield, E. Raggett, and B. T. O'Kennedy. 2000. Implementation of integrated membrane processes for pilot scale development of fractionated milk components. Lait 80:139-153.

Kudryashov, E., C. Smyth, G. Duffy, and V. Buckin. 2000. Ultrasonic high-resolution and shear wave measurements in food colloids: Monitoring of gelatinization processes and detection of pathogens. Progr. Colloid Polymer Sci. 115:287-294.

McMahon, D. J., and R. J. Brown. 1984. Composition, structure and integrity of casein micelles: A review. J. Dairy Sci. 67:499-512.

Nassar, G., B. Nongaillard, and Y. Noel. 2001. Monitoring of milk gelation using a low-frequency ultrasonic technique. J. Food Eng. 48:351-359.

Povey, M. J. W. 1997. Ultrasonic Techniques for Fluids Characterization. Acad. Press, San Diego, CA.

Povey, M. J. W., M. Golding, D. Higgs, and Y. Wang. 1999. Ultrasonic spectroscopy studies of casein in water. Int. Dairy J. 9:299-303.

Pyne, G. T., and K. A. McHenry. 1955. The heat coagulation of milk. J. Dairy Res. 22:60-68.

Rattray, W., and P. Jelen. 1997. Thermal stability of skim milk/whey protein solution blends. Food Res. Int. 30(5):327-334.

Rose, D., and H. Tessier. 1959. Composition of ultrafiltrates from milk heated at 80 to $230^{\circ} \mathrm{F}$ in relation to heat stability. J. Dairy Sci. 42:969-980.

Schaaffs, W. 1967. Landolt-Börnstein Numerical Data and Functional Relationships in Science and Technology. New series. Group II: Atomic and Molecular Physics. Volume 5: Molecular Acoustics. Springer Verlag, Berlin.

Singh, H., and L. K. Creamer. 1991a. Aggregation and dissociation of milk protein complexes in heated reconstituted concentrated skim milks, J. Food Sci. 56 (1):238-246.

Singh, H., and L. K. Creamer. 1991b. Changes in size and composition of protein aggregates on heating reconstituted concentrated skim milk at $120^{\circ}$ C. J. Food Sci. 56 (3):671-677.

Sigfusson, H., G. R. Ziegler, and J. N. Coupland. 2004. Ultrasonic monitoring of food freezing. J. Food Eng. 62:263-269.

Smithsonian Institution. 1920. Smithsonian Physical Tables. 7th rev. ed. Smithsonian Institution, Washington, DC.

Smyth, C., K. Dawson, and V. A. Buckin. 1999. Ultrasonic analysis of heat-induced coagulation in calcium fortified milk. Progr. Colloid Polymer Sci. 112(39):37-43.

Sommer, H. H., and E. B Hart. 1919. The heat coagulation of milk. J. Biol. Chem. 40:137-151.

Sommer, H. H., and E. B. Hart. 1922. The heat coagulation of milk. J. Dairy Sci. 5:525-543.

Standard Association of Australia. 1978. Determination of the heat stability of skim-milk powder, Australian Standard 1629.3.4.1978.

van Boekel, M. J. A. S., J. A. Nieuwenhuijse, and P. Walstra. 1989. The heat coagulation of milk. 1. Mechanisms. Neth. Milk Dairy J. 43:97-127.

Waterman, P. C., and R. Truell. 1961. Multiple scattering of waves. J. Math. Phys. 2:512-537.

Webb, B. H., and G. E. Holm. 1932. The heat coagulation of milkII. The influence of various added salts upon the heat stabilities of milks of different concentrations. J. Dairy Sci. 15:345-366.

White, J. C. D., and D. T. Davies. 1966. The stability of milk protein to heat-III. Objective measurement of heat stability of milk. J. Dairy Res. 33:93-102.

Yaws, C. L. 1977. Physical Properties: A Guide to the Physical, Thermodynamic and Transport Property Data of Industrially Important Chemical Compounds. Chemical Engineering, New York, NY. 